\title{
Honorato de Lérins, Heracles y las islas errantes
}

\author{
Pierre MORET \\ CNRS - Université de Toulouse, UMR 5608 TRACES
}

\begin{abstract}
Resumen
Tres islas del Mediterráneo occidental fueron llamadas Planêsia o Planasia por los griegos: Pianosa en el mar tirreno, Lérins cerca de Cannes y Tabarca cerca de Santa Pola. Las tres son pequeñas, bajas, peligrosas para la navegación y eran desiertas en la época arcaica, aunque situadas en rutas marítimas importantes, en zonas frecuentadas o colonizadas por los foceos. Etimológicamente, Planêsia es "la isla errante", y se relaciona con una tradición cosmogónica en la que las islas, flotantes en el mar en su estado primitivo, habían sido enraizadas en el zócalo del mundo habitable gracias a la acción de un dios o de un héroe civilizador. El mito de fundación de Tiro es partícipe de esta creencia con el protagonismo de Heracles-Melqart. Una serie de indicios sacados de la leyenda cristiana de san Honorato de Lérins permite pensar que un mito similar puede explicar el nombre de la isla Planasia de Lérins.
\end{abstract}

Palabras clave: Planesia, islas, Grecia, mitología, Heracles, Tiro.

\section{Summary}

Three islands of the Western Mediterranean, Pianosa in the Tyrrhenian sea, Saint-Honorat in Liguria and Tabarca in Iberia, were called in hellenistic times by the same greek name, Planêsia or Planasia, which means "the wandering island". All three have geographical connections with colonies or trading posts of the Western Phoceans. This name refers to cosmogonic myths in which a hero or a god is said to have brought the roaming island to a standstill, making it suitable for civilized life. From this point of view, the role played by Heracles-Melqart in the foundation myth of Tyre supports a comparison with a local legend that shows saint Honorat driving the snakes away and causing a spring of sweet water to gush forth in the "wandering island" of Lérins.

Keywords: Planesia, islands, Greece, mythology, Heracles, Tyre.

Hace quince años, un estudio que realicé sobre la intrigante serie toponímica de las islas del Mediterráneo occidental llamadas Planêsia o Planasia por los griegos (Moret, 1997), me llevó a seguir los derroteros de la colonización y del comercio foceo, a adentrarme en el extraño mundo de las creencias antiguas sobre las islas, e incluso a indagar en las huellas insulares de Heracles y Melqart. Me complace ofrecer aquí a Manuel Bendala, nacido en una de aquellas islas que el dios de Tiro ató a la tierra, algunos datos nuevos, cosechados a lo largo de los últimos años, que permiten precisar algo más el marco mitoló- gico en el que se insertan las "islas errantes" del Mediterráneo griego, y confirmar la perduración de alguno de sus componentes en la leyenda cristiana de san Honorato en Lérins. Antes de presentar estos datos y reflexiones nuevas, creo necesario resumir los principales resultados del citado estudio.

\section{Las tres Planesias}

Son tres las islas que los griegos llamaron Planêsia, o Planasia por variación dialectal: Saint-Honorat cerca de Cannes en la Provenza, 
Pianosa al sur de la isla de Elba, y Tabarca en frente del cabo de Santa Pola.

La isla tirrena de Planasia, hoy Pianosa, en el archipiélago toscano al sur de la isla de Elba, es conocida en la historia como lugar del destierro y de la muerte de Agrippa Postumus en 14 d.C. Mencionada por muchas fuentes antiguas (entre otras Estrabón, II 5, 19 y Plinio, III 81), es la más grande de las tres, con $10 \mathrm{~km}^{2}$. Tiene el aspecto de una mesa plana y baja, con costas irregulares, a menudo rocosas (Sommier, 1909). Alternó en su historia fases de colonización -especialmente en época romana imperial-y de abandono. No hay evidencias de una ocupación en época griega (Nenci \& Vallet, 1994, 535-546).

Las islas de Lérins, que prolongan la punta de la Croisette de Cannes entre el golfo de la Napoule y el golfo Juan, son famosas por su monasterio, uno de los más antiguos de la Galia. Al norte, la isla Sainte-Marguerite es más grande, con un buen puerto. Al sur, la pequeña isla de Saint-Honorat (unas 40 hectáreas) es baja y de difícil acceso por el carácter rocoso de sus costas, pero posee un manantial de agua dulce. No se documenta una presencia estable en SaintHonorat antes de la fundación del monasterio en el siglo V d.C., mientras que en Sainte-Marguerite existió un poblado y un santuario dedicado a Lérôn y Lériné, en uso entre los siglos III y I a.C., aunque el lugar estuvo frecuentado desde el siglo VI (Coupry \& Vindry, 1982; Arnaud, 2003). Plinio el Mayor (III 79) y el Itinerario marítimo de Antonino (504 Wesseling) las llaman Lero y Lerina. Estrabón (IV 1,10) coincide con ellos en dar a la una el nombre de Lêrôn (equivalente a la forma latinizada Lero), pero llama la otra Planasia, en vez de Lerina, y añade que "hay en Lêrôn un santuario del héroe Lêrôn". Un exvoto de época helenística descubierto en SainteMarguerite, con la inscripción "Ateneo hijo de Dionisio, de Neôpolis, a Lêrôn y a Lêrinê", confirma la existencia de este culto, y muestra además que cada isla tenía su divinidad epónima, ambas formando una probable pareja a juzgar por sus nombres, masculino el uno, femenino el otro (Coupry \& Vindry, 1982). Los textos cristianos del siglo V (San Hilario, Paulino de Nola, Sidonio Apolinario) permiten identificar Leron con Sainte-Marguerite, y Lerina con Saint-Honorat. Todo parece indicar que el nombre Planasia, pre- sente en una fuente de Estrabón probablemente anterior al cambio de era, había caído en desuso cuando los ermitaños se asentaron en la isla más pequeña.

La isla de Tabarca, situada a cuatro kilómetros de Santa Pola, es pequeña (23 hectáreas), baja, rocosa y árida. Fue llamada sucesivamente Isla de San Pablo, Isla Plana e Isla de Santa Pola, antes de recibir en 1768 el nombre de Isla de Nueva Tabarca. Tuvo en la Antigüedad un quinto nombre, el de "islote Planesia" que le da Estrabón en su descripción de la costa oriental de Iberia (III 4, 6). Fue Mayans i Siscar (1771: 203 sq) quien dio los argumentos decisivos para identificar esta Planesia con la isla que hoy se llama Tabarca, gracias a dos testimonios intermedios de las transformaciones del nombre griego: Ablanasa en AlIdrîsî (Dubler, 1988: 128), y Planesa después de la Reconquista. Al final de esta evolución, la forma abreviada Plana se debe a una confusión etimológica, sobre la que volveremos más adelante. La isla era deshabitada cuando Carlos III la pobló con trescientos pescadores genoveses expulsados de la tunecina Tabarka. Antes de esa fecha, las únicas huellas de una ocupación estable -aunque limitada- datan de la época romana imperial (Pérez Burgos, 1997).

A estos tres casos seguros podemos añadir, con reservas, una de las Islas Afortunadas, llamada Planasia según Sebosus Statius, citado por Plinio (VI 202) que precisa que se llama así a specie, por su aspecto. Esta glosa tendría más sentido si el texto dijera Planaria, y así lo han corregido algunos editores; además, este nombre no aparece en la otra lista utilizada por Plinio, la de Juba. Sobre este dossier complejo, que prefiero dejar de lado para centrarme en los casos que no sufren controversia, remito al reciente comentario de Jehan Desanges (2008, 235-236). Existen además en la toponimia moderna del Mediterráneo occidental algunos nombres que recuerdan a Planesia, como el islote de la rada de Marsella que se llama Planier en la actualidad pero aparece como Planessa, Planesis, Planesa, Planies en documentos medievales (Rigaud, 2003, 50). Por sugerente que sea la homofonía, dejaremos también este caso en suspenso, porque no hay posibilidad de saber a ciencia cierta si el origen del nombre se remonta a la Antigüedad. 
Nuestras tres Planesias tienen varios puntos en común. Son islas relativamente pequeñas, bajas, poco aptas para el cultivo, desiertas en la época de las primeras navegaciones griegas, con escasos fondeaderos y con arrecifes o fondos peligrosos en sus inmediaciones. Los derroteros de los siglos XVIII y XIX insisten en la dificultad de bordear sus costas. Hay constancia de ocho naufragios en los arrecifes de Tabarca entre 1877 y 1922 (Ramos, 1970, 71), y se conocen por lo menos cuatro pecios antiguos alrededor de las islas de Lérins (Parker, 1992, n 97, 1004, 1010 y 1174).

Por otra parte, están situadas en rutas marítimas importantes: Lérins en el derrotero ligur que aprovechaba las corrientes costeras de este a oeste; Pianosa en la ruta que desde Massalia conducía a las costas de Etruria y del Lacio, y que según el régimen de los vientos podía pasar entre la isla de Elba y la tierra firme, o entre Elba y Pianosa (Dion, 1954), así como, en sentido contrario, en una ruta que tenía como destino Narbona y Tarragona (Arnaud, 2005: 165); y Tabarca en la ruta costera del sureste ibérico, siendo posible $-\mathrm{y}$ recomendado por los derroteros del siglo XIX- el paso entre la isla y el cabo de Santa Pola (Michelot, 1824: 44). No es de extrañar pues que estas tres islas, situadas en parajes tan frecuentados, hayan recibido nombre de los navegantes griegos.

Última coincidencia: están situadas en tres de las zonas del Mediterráneo occidental donde los foceos estuvieron más activos, Lérins cerca de la colonia masaliota de Antipolis (Antibes), Pianosa a medio camino entre los puertos del norte de Etruria y la colonia focea de Alalia en Córcega, y Tabarca en frente del asentamiento de La Picola en Santa Pola, una factoría ibérica frecuentada por mercaderes griegos (Badie et al., 2000; Domínguez Monedero, 2002: 84 sq). Esta coincidencia había sido percibida ya por Wolfgang Aly, hace más de medio siglo: "Die Verbreitung lehrt, daß der Name in den Interessenkreis von Massalia gehört" (Aly, 1957: 122). De ser admitida esta relación entre las islas Planesias y los foceos del Oeste, podríamos atribuir este nombre a la etapa arcaica, o en todo caso prehelenística, de la historia de la toponimia griega del Extremo Occidente (Moret, 2006).

\section{De LA ETIMología AL Mito}

Aunque no se discutiera el origen griego del nombre, su parecido con el adjetivo latino planarius ha llevado a muchos autores a creer equivocadamente que tenía algo que ver con el perfil bajo y plano de las tres islas. Este error no es reciente: incurrió en él el propio Plinio, poco ducho en griego, cuando hesita entre las voces Planaria (III 80) y Planasia (III 81) para nombrar la isla tirrena, lanzándose en una explicación etimológica confusa, que suma al sentido de "plana" el de "engañadora": Planaria a specie dicta, aequalis freto ideoque navigiis fallax. Con este segundo sentido, Plinio no estaba muy lejos de la verdad. Planesia pertenece a la familia de planâ̂ ("extraviar") / planaomai ("errar"). Varios filólogos e historiadores modernos han optado por el sentido activo, siguiendo a Plinio y entendiendo Planêsia como la isla que extravía a los navegantes, a causa de su baja altura que hace que la confundan con el mar. Sin embargo, esta lectura no es aceptable gramaticalmente. El sufijo -êsia de Planêsia pertenece a una formación adjetival con tema en -t- que debe corresponder a un substantivo en -ês o -êtos (Chantraine, 1933: 40-41 y 86). Ahora bien, la familia de planaô contiene las dos formas, planês y planêtos, con idéntico significado: "errante, vagabundo". La interpretación del topónimo debe realizarse a partir del campo semántico de estas palabras. Planêsia no es "la isla que extravía", sino "la isla errante" o "la isla de los errantes". Existe un topónimo latino que avala indirectamente esta lectura. El Itinerario marítimo de Antonino (512 Wesseling) menciona una Insula Erroris -no identificada- entre Cartagena y Cesárea de Mauretania. Sabiendo que el substantivo error era la traducción habitual del griego planê, "extravío, curso errante", en sus acepciones tanto astronómicas como marítimas, hay buenos motivos para pensar que esta enigmática Insula Erroris del Mediterráneo Occidental pertenece a la misma serie toponímica que las Planesias griegas, y con el mismo sentido. Pero ¿a qué se refiere esta noción de marcha o curso errante? ¿A los hombres o a las propias islas?

Gramaticalmente, las dos interpretaciones son posibles: la relación entre el nombre nêsos, "isla", y el adjetivo que está contenido en Planêsia puede ser tanto circunstancial (la isla de 
los viajeros errantes) como atributiva (la isla errante). La primera opción no goza del apoyo, siquiera indirecto, de las fuentes escritas. En cambio, encontre a favor de la segunda una evidencia de gran peso en un lugar insospechado: el Curculio de Plauto. En esta comedia adaptada de la comedia nueva griega, Planesium es el nombre de la joven heroína, robada a sus padres en Caria cuando niña y vendida como esclava en Epidauro: esta muchacha es, propiamente dicho, "la extraviada", "la errante" (Schmidt, 1902: 377), en un género literario en el que los nombres de los personajes suelen dar la clave de su carácter o de su destino (Petrone, 1988).

La aplicación a las islas de semejante denominación no es tan sorprendente como puede parecernos a primera vista. El enraizamiento de las islas en el fondo del mar no era, para los griegos, un hecho evidente. Existía una tradición cosmogónica, atestiguada entre otros por Homero, Píndaro y Calímaco, que daba a ciertas islas del Mediterráneo una ascendencia marina. Nacidas del mar, habían pasado primero por un estado intermedio, ambiguo, a medio camino entre la matriz líquida indiferenciada y la estabilidad de la tierra firme que acogería a la raza humana: el estado de isla flotante, movediza, errática (Cook, 1940: 975-1015; Détienne \& Vernant, 1974: 153155; Nishimura-Jensen, 2000; Montiglio, 2005: 14). Su enraizamiento en el zócalo del mundo habitable, su anexión a la ecúmene, sería una de las consecuencias de la victoria de los dioses del Olimpo sobre las fuerzas dislocadoras del Caos.

La más conocida de estas islas flotantes es la primera Delos, cantada por Píndaro en un himno del que solo se conservan fragmentos (87-88 Schroeder): "hija del mar" (v. 3), "llevada por las olas" (v. 6), será Apolo quien la atará al fondo del mar por medio de cuatro columnas (v. 8-11). Pero no es la única. "Flotante", plôtê nêsos, fue la isla de Eolo en la Odisea (X, 3), al igual que la isla de Patmos en sus orígenes míticos, las islas Eolias del mar Tirreno o las islas Strophades al sur de Zante. Se vislumbra, detrás de estos casos individuales, un esquema más general, propio de un relato cosmogónico, que ha dejado rastro en un escolio de Apolonio de Rodas, a propósito del nombre Planktê dado por Apolonio a la isla eolia de Hiera y que significa también, en este contexto, "flotante" o "errante". Dice el escoliasta, para explicar este nombre, que "antaño todas las islas eran errantes y no tenían bases" (Schol. vet. in Apoll. Rhod., III 41-43).

El registro semántico del errar no es propio de las islas. Tiene su correspondencia poética y mitológica en el cielo. Según la leyenda, mientras estuvo flotando y errando en el mar, Delos se llamó Asteria, la isla-estrella (Píndaro, Peán V, 42; Calímaco, Himno a Delos, 36-38). En una vertiginosa y magnífica metáfora, Píndaro evoca la isla "que los mortales llaman Delos, y que los bienaventurados en el Olimpo llaman el astro, resplandeciente a lo lejos, de la oscura tierra" (fr. 87-88 Schroeder, 4-5). Tirando del hilo de un juego etimológico -Dêlos "la brillante", Asteria "la estrella"-, Píndaro imagina la escena que ven los dioses desde su morada en lo alto del Olimpo: Delos-Asteria, brillante y vagabunda, deja a sus ojos la misma estela sobre el fondo azul oscuro del mar que a los nuestros la revolución de un astro errático en el cielo nocturno. Delos-Asteria no es el único caso en el que la toponimia entretiene la ambigüedad de un juego de espejos entre las esferas celeste y marina. Asteris, islote cerca de Itaca en la Odisea (IV 844-846), tiene sin duda el mismo referente. Y last but not least, nuestras Planêsiai mantienen exactamente la misma relación etimológica y semántica con planêtes, nombre genérico que los griegos daban a todos los astros erráticos, que Asteria con astêr. Esta fascinante simetría de las bifurcaciones semánticas aporta el último argumento a nuestra interpretación de Planêsia como la isla errante.

Como bien se sabe, la isla flotante también está presente en otras mitologías antiguas. Según la versión del mito de fundación de Tiro que nos ha dejado Nono de Panópolis (Dionysiaca, XL 423-500), las rocas ambrosianas, "dos rocas inestables y vagabundas [que] flotaban en el mar", quedaron fijas y "enraizadas" en el fondo del mar después de un sacrificio ordenado por HeraclesMelqart, haciendo posible el asentamiento humano en las islas que se convertirían en la ciudad de Tiro (Will, 1950-51; Bonnet, 1988: 87-90).

\section{¿HERACLES EN LÉRINS?}

Acabamos de ver que la figura de la isla errante, en el caso de Delos como en el de Tiro, se inserta en relatos míticos cuyo momento clave es 
la intervención de una divinidad que tiene el poder de fijar y enraizar la isla. Una serie de indicios, sacados de la leyenda cristiana de san Honorato de Lérins, permiten pensar que un relato parecido existió en la Planesia masaliota.

Se conocen dos versiones de la vida de san Honorato. La más antigua es un sermón de su discípulo Hilario de Arles, pronunciado en 431, un año justo después de la muerte del fundador del monasterio de Lérins (Valentin, 1977). Dada esta proximidad - Hilario vivió en Lérins unos diez años al lado de Honorato-, no es de extrañar que se trate de un relato relativamente aséptico y poco proclive a detalles maravillosos. Contiene sin embargo un par de datos llamativos. A la llegada de Honorato, la isla era desierta "a causa de los animales venenosos que en ella pululaban", unas serpientes que habían nacido "de los cálidos soplos del mar". Pero la sola presencia del santo basta para que "la multitud de las serpientes se retire" (Sermo de vita sancti Honorati, 15). A continuación, "un manantial, agotado desde hace siglos, vuelve a manar abundantes aguas", y la isla, de árida e inhóspita, se convierte en acogedora y fértil (ibid., 17).

En mi artículo de 1997, me había basado en estos dos prodigios, el triunfo sobre las serpientes y el surgimiento de la fuente, para hacer tres hipótesis: 1/ que estas serpientes eran el avatar cristiano de criaturas ctónicas, posibles divinidades tópicas, siguiendo sobre este particular a $\mathrm{J}$. Coupry y G. Vindry (1982: 358) que las relacionaron con las divinidades epónimas de las islas, Lerón y Lerina; 2/ que la creencia popular había atribuido a Honorato una hazaña propia de un héroe o de un dios pagano, posiblemente un Heracles sauróctono, matador de monstruos ctónicos como la Hidra o la serpiente de las Hespéridas; 3/ que el nombre Planasia permitía intuir un esquema mítico comparable con el de la fundación de Tiro, donde se repiten los mismos cuatro elementos: la isla errante, el dios que la fija y la hace habitable, la serpiente y la fuente, si como veremos más adelante combinamos las informaciones dadas por Nono de Panópolis y la iconografía.

No obstante, hay que reconocer que la naturaleza y el estilo de la narración de Hilario de Arles pueden suscitar dudas acerca de la existencia de un componente pagano subyacente.
Llama la atención el hecho de que el episodio de las serpientes hace confluir en Honorato varias referencias intertextuales bíblicas y cristianas, desde el verso "Pisarás el áspid y el basilisco" del Salmo 90 hasta el milagro de San Pablo que corta el veneno de la víbora de la isla de Malta (Act. 28, 3-6), pasando por uno de los más conocidos topoi de la tradición eremítica egipcia: la lucha contra animales venenosos o feroces en un lugar desierto (Labrousse, 1995: 117, n. 56). Con este juego de referencias que se podría hacer extensivo al tema del agua que mana milagrosamente, no hay que subestimar la posibilidad de estar ante una simple "figura de estilo" (Rigaud, 2003: 61), sin relación directa con una tradición local precristiana.

Pero mi primer acercamiento a esta cuestión resultó ser incompleto. No había consultado entonces dos versiones más tardías de la vida de San Honorato, más interesantes para mi propósito en la medida en que tienen una coloración legendaria mucho más rica y detallada. Se trata, por un lado, de una Vita sancti Honorati anónima, redactada en latín, probablemente por un monje de Lérins (Munke, 1911), y por otro lado de un poema en provenzal literario, la Vida de Sant Honorat, escrita por el trovador nizardo Raimon Feraut (Suwe, 1943), que sigue muy de cerca la trama de la vida latina anónima. Ambas están datadas entre los últimos años del siglo XII y los primeros del XIII. Su principal fuente de inspiración es el sermón de san Hilario, al que añaden dos ingredientes: episodios y personajes tomados de las canciones de gesta del ciclo de Carlomagno, a través del Pseudo-Turpín (Munke, 1911: 27), y tradiciones populares locales. Resumo a continuación el episodio del triunfo de Honorato sobre las serpientes de Lérins, tal como lo narran la Vita latina (capítulos VIII a X) y el poema de Feraut (XXVIII a XXIX y XXXVIII).

Honorato, preso de los maniqueos, es abandonado en una isla que los paganos llaman Auriana, y entregado a la multitud de serpientes que habían sido atraídos desde la tierra firme por los cadáveres de los mahometanos matados por Carlomagno en la vecina isla de Atrapa. Las dos serpientes más grandes y feroces se llamaban Lirus y Rinus (Leri y Rin en Feraut). Solían cruzar el brazo de mar par coger bueyes, caballos e incluso hombres en la tierra firme, y luego traer- 
los a la isla para devorarlos; y hacían lo mismo con los marineros imprudentes que se acercaban a la isla. Su crueldad era tan famosa que el nombre de la isla, Lirinus, se formó con los suyos, Lirus y Rinus. Enfrentado a la multitud de las serpientes, sin ningún lugar donde refugiarse en una isla desierta, Honorato, desesperado, se pone a rezar. Recibe entonces una visión en la que san Caprasio y san Venancio le hablan: "Nuestro Señor hará crecer muchos árboles y muchas palmeras; entonces tú cavarás en medio de la isla y saldrá agua de la roca en abundancia". Honorato recapacita y con el signo de la cruz mata todas las serpientes en un instante. Pero los cadáveres de los reptiles empiezan enseguida a pudrirse, llenando la isla de pestilencia. Honorato pide a Dios que lo libre de esta plaga. De repente las olas crecen, el mar sube y empieza a cubrir la isla: Honorato sube en una palmera que había en medio de la isla, mientras el mar se extiende sobre la isla y la barre toda. Luego las olas se retiran, trayendo consigo los cadáveres, y el mar vuelve a sus límites. Honorato baja entonces de la palmera y toma la decisión de fundar el monasterio. Poco tiempo después de su fundación, el agua empieza a faltar. Honorato ordena a sus compañeros que excaven en medio de la isla, entre las dos palmeras más altas. Cavan hasta la roca sin éxito y se desaniman. Entonces Honorato invoca a la santa Trinidad, dando tres golpes en la roca, y enseguida surgen abundantes aguas.

A pesar de estar basado en los dos milagros señalados brevemente por Hilario - la muerte de los reptiles y el surgimiento de la fuente-, el episodio de la llegada del santo en la isla de Lérins ha sido objeto en esta versión de una profunda remodelación, con digresiones, amplificaciones y añadidos, hasta caer en incoherencias y contradicciones. De hecho, el excursus sobre los monstruos Lirus y Rinus no parece tener otro motivo que el de explicar el nombre de la isla: no tienen un papel activo en la narración, ya que cuando se describe lo que Honorato tiene que enfrentar, sólo se habla de una masa de reptiles indiferenciada y anónima. Además, hay una contradicción insalvable entre lo que se dice del origen de esta multitud de serpientes - han sido atraídos desde la tierra firme por los cadáveres de una reciente matanza - y la descripción de las fechorías de Lirus y Rinus que, todo al contrario, aparecen como los dueños permanentes de la isla, de donde salen de vez en cuando para sembrar el terror en el continente. Otra contradicción: se da a la isla dos nombres distintos, Auriana y Lirinus, a pocas líneas de distancia, sin que este hecho reciba una explicación coherente. Auriana es un nombre enigmático: la Vita y el poema de Feraut son las únicas fuentes que lo mencionan (Krettek, 1911: 190-192). Todo lo que se puede decir al respecto es que su sufijo iana hace pensar en nombres de grandes fincas de la Antigüedad tardía (cf. Arnaud, 1998). El nombre dado a la isla de Sainte-Marguerite no es menos sorprendente: en vez del Lero o Leron de las fuentes antiguas, Atrapa es otro hápax, tal vez relacionado con prov. trap "barraca, casa" (Levy, 1894-1924, s.v.), y a través de éste con el galo treb- "habitación", con un primer elemento que recuerda la formación del etnónimo galo Atrebates: *ad-treb-ates (Delamarre, 2003: 301).

En cualquier caso, estas contradicciones demuestran que el relato medieval bebe de diversas fuentes, con elementos heteróclitos que se combinan sin mucho cuidado. El uso de estos nombres desconocidos, que no tienen relación alguna con fuentes literarias más antiguas, demuestra claramente que el autor de la Vida no se basaba en fuentes clásicas y no hacía un trabajo de corte erudito. En medio del flujo épicomaravilloso de una narración que sigue el esquema y el tono de las canciones de gesta, surgen episodios o historietas que remiten claramente a tradiciones locales (Moris, 1909: 343; Munke, 1911: 27), recopiladas y adornadas por los monjes de Lérins: "Les couvents médiévaux n'ont cessé de lire, recopier, enjoliver ces Vies, qui ont progressivement tissé la toile d'un imaginaire pagano-chrétien où se sont fixées les représentations d'un christianisme populaire »(Nouailhat, 1988: 48).

Estas circunstancias dan pie para formular, con más fuerza que en 1997, la siguiente hipótesis: los elementos maravillosos que vinieron añadiéndose a lo largo de los ocho siglos que separan el relato original de Hilario de la Vida anónima de ca. 1300, son susceptibles de ser interpretados, por lo menos parcialmente, como los últimos avatares, en clave cristiana, de un mito relacionado con esta isla desde los tiempos de la colonización focea o masaliota. 
Se sabe que los contextos insulares siempre han sido un terreno propicio para la conservación de antiguas creencias o leyendas. El ejemplo de Rodas es uno de los más ilustrativos y curiosos. Un mito griego contaba que el héroe Forbas había librado esta isla de terribles serpientes. Muchísimo tiempo después, en pleno siglo XVII, una tradición popular atribuye exactamente la misma hazaña a Dieudonné de Gozon, que fue gran maestro de la orden de San Juan de Jerusalén en 1345: los vecinos de la ciudadela enseñaban a los viajeros una cabeza disecada, expuesta encima de la puerta de la ciudad, afirmando que era la cabeza del monstruoso dragón matado por Gozon (Thévenot, 1727: 370)... En esa isla como en la de Lérins, cada época se apropia un esquema mítico preexistente, renovándolo y cambiando su apariencia, del héroe pagano al héroe o al santo cristiano.

Tratemos de ver lo que, en la versión tardía de la leyenda de san Honorato, puede tener ascendencia antigua. Esta versión contiene, en realidad, dos elementos míticos distintos, torpemente asociados por el redactor de la Vida, como hemos visto: por un lado, la confrontación entre un héroe y dos serpientes monstruosos, epónimas de la isla; por otro lado, un milagro que pone en escena un maremoto, las serpientes, el árbol y la fuente, y que tiene como consecuencia la transformación de una isla desierta e inhabitable en un lugar acogedor y civilizado.

El primer elemento es el que, sin lugar a dudas, se relaciona más directa y fehacientemente con una tradición griega precristiana. Como habían visto J. Coupry y G. Vindry (1982: 358), las dos serpientes monstruosas de la Vita sancti Honorati han conservado casi intactos los nombres de la pareja de divinidades epónimas de las islas, Lerón y Lerina. Su naturaleza reptil, revelada por el texto medieval, las emparenta con otros seres de ascendencia divina ctónica, guardianes de lugares apartados, como la Hidra de Lerna o la serpiente de las Hespéridas que velaba sobre las manzanas de oro. Más interesante aún es su enfrentamiento con un héroe. Como otros autores lo han advertido en varias ocasiones, la tradición legendaria cristiana del sureste de Francia rebosa de duelos entre dragones, serpientes monstruosas o "tarascas" y el santo más venerado del lugar: san Hermentario en Draguignan, santa Marta en
Aviñón, san Verán en Cavaillon, etc. (Reyt, 2000: 134; Privat, 2006). Estas historias suelen ser variaciones del famoso tema del triunfo de san Jorge sobre el dragón, a las que se añaden evidentes reminiscencias heracleas, facilitadas por un proceso de identificación y sustitución del héroe greco-romano por figuras de santos, que se observa en la hagiografía y la iconografía de todo el Occidente cristiano (Simon, 1955). Autores como Fernand Benoit o Ellen Ettlinger han recalcado que el recuerdo del culto a Heracles fue especialmente vivaz en la Provenza y, más concretamente, se han subrayado "the analogies between the Heraclean myths and the legends about St. Honorat" (Ettlinger, 1964: 263).

¿Son suficientes estos indicios para admitir que Heracles se esconde detrás de san Honorato, y que Lero y Lerina se suman a Gerión, Eryx y toda la lista de los seres ctónicos, dueños del suelo y de las aguas, a los que el héroe tuvo que vencer para abrir a los griegos las puertas del Occidente? Sería imprudente afirmarlo, pero creo que la hipótesis es algo más que simplemente sugerente. La geografía mítica de Occidente atestigua una vinculación especial de Heracles con las islas. Aunque el Heracles que viaja por mar entre Eriteia, Tartessos, la Liguria e Italia no esté tan presente en las fuentes literarias como el viajero terrestre, su existencia está claramente atestiguada (Lacroix, 1974). La toponimia insular marca las etapas de su navegación, con dos "islas de Heracles" en las costas meridionales de Iberia (Estrabón, III 4, 6 y 5, 5), otra en la punta noroeste de Cerdeña (Plinio, N. H., III 84), otra más entre las islas Lipari (Mela, II 120); y el nombre de las islas Baleares vendría, según una de las dos versiones recogidas por Livio (Periochae, 60), de Balio, "un compañero de Heracles abandonado ahí mientras Heracles navegaba hacia el país de Gerión". No olvidemos, además, que dos de los puertos que llevaban el nombre del héroe estaban muy cerca de la Planasia ligur: Heraclea Caccabaria al oeste, probablemente en Cavalaire (Itinerario marítimo, p. 505 Wesseling), y Monaco al este con su santuario de Heracles monoikos (Estrabón, IV 6, 3).

Sería pues a este Heracles navegante, explorador y civilizador del Extremo Occidente, fruto de un proceso de asimilación con el Melqart de Tiro y Gades (Bonnet, 1988; Jourdain-Annequin 
1989), al que una tradición local podría haber opuesto a los dioses-serpientes de Lérins. Ahora bien, el segundo esquema mítico que hemos identificado en la leyenda medieval, con la isla cubierta por el mar y posiblemente flotante, las serpientes, el árbol y la fuente, encuentra un sorprendente eco en la leyenda de fundación de la propia Tiro.

Según el relato de Nono de Panópolis al que ya hemos hecho alusión más arriba, la fundación de Tiro resultó de una intervención de Melqart que había enseñado a los "hijos de la tierra" a construir una nave para ir al lugar donde dos islotes, las "rocas ambrosianas", flotaban en el mar. Encima de la roca errante se elevaba un olivo que albergaba un águila, una copa y una serpiente, y de donde salían llamas. Tendrían que sacrificar el águila para que la roca dejara de vagar por las ondas (Dionysiaca, XL 423-500). Varias representaciones, especialmente en monedas de Tiro, ilustran esta escena, a la que añaden un elemento más: una fuente que mana entre las dos rocas convertidas en estelas (Will, 1950-51; Bonnet, 1988: 87-90), simbolizando la transformación de los islotes errantes y estériles en el solar acogedor de la futura ciudad. No es este el lugar para entrar en el debate sobre la significación de esta compleja escena que parece tener por lo menos dos fuentes: una local, tiria, y otra griega, posiblemente Eratóstenes, que reúne en el árbol el ave, la serpiente y la copa en una composición que reproduce la constelación de la Hidra asociada en el cielo austral al Cuervo y a la Copa (Frangoulis, 2008).

Sea lo que fuere, el hecho es que la mayor parte de los temas presentes en Tiro vuelven a encontrarse en Lérins: 1/ a las dos rocas ambrosianas de Tiro corresponden las dos islas casi gemelas de Lérins; 2/ las rocas ambrosianas flotan y vagan en el mar como lo hace Planasia a juzgar por el significado de su nombre griego; 3 / las dos islas poseen un árbol sagrado: una palmera en Lérins, un olivo en Tiro; 4/ una serpiente (en Tiro) o varios reptiles (en Lérins) están presentes en la isla; 5/ la intervención de una divinidad civilizadora permite que los hombres se asienten en la isla; 6/ una fuente de agua dulce surge a raíz de esta intervención divina. Sólo faltan en Lérins las llamas que envuelven el árbol sin abrasarlo, la copa y el águila, pero hemos visto que estos dos últimos elementos pueden proceder de una fuente griega helenística y no están presentes en la iconografía tiria, sea en monedas o en relieves.

Parece difícil achacar este paralelismo a una simple coincidencia. No quiero decir que el mito de la Planasia ligur reproduce el de Tiro: con elementos casi iguales, la estructura narrativa es diferente. Creo más bien que estamos ante uno de los componentes de una koine mítica que estuvo compartida por las diversas culturas que estaban en contacto en el espacio del Mediterráneo antiguo. Se sabe que el tema de la lucha con la serpiente, la Hidra o el dragón ha sido uno de los vectores más eficaces del acercamiento entre las figuras de Heracles y Melqart, como lo muestra, por ejemplo, el hallazgo en el asentamiento fenicio de Motye de una terracota de fabricación local, fechada en el siglo VI o V a.C., que representa la lucha de Heracles con la Hidra de Lerna (Bonnet, 1988: 276).

De hecho, varios de los elementos que acabamos de identificar en Lérins y en Tiro se encuentran también en otros asentamientos insulares o costeros, especialmente en los de la diáspora tiria como Gades y Lixus. Un tema especialmente interesante es el de los flujos de agua marina que, según distintas tradiciones locales, circulaban por encima o por debajo de una ciudad insular, haciendo peligrar su estabilidad y amenazando de devolverla a la condición errante de las islas primigenias. La naturaleza híbrida de Tiro, a medio camino entre tierra y mar, queda claramente expresada por Aquiles Tacio: "Tiro no está enraizado en el mar; el agua corre por debajo, por un canal situado debajo del istmo, dando el extraño espectáculo de una ciudad en el mar y de una isla en la tierra" (Leucipa y Clitofonte, II 14, 4). En Gades, las grandes mareas del solsticio de verano anegaban la base del templo de Heracles en la isla de Kotinoussa (Estrabón, III 5, 9), y el nivel del agua en la fuente del santuario variaba en función de la marea (ibid., III 5, 7), lo que significa que, para los gaditanos, no había duda de que el mar circulaba por debajo y por encima de la isla. Cerca de Lixus, en el golfo Empórico, el altar de Heracles estaba situado delante de una cueva que la marea alta solía invadir (Estrabón, XVII 3, 3). El maremoto que cubre completamente la isla de Lérins es el equivalente catastrófico, pero temáti- 
camente homólogo, de la periódicas invasiones marinas que caracterizan estos tres asentamientos donde se veneraba a Heracles-Melqart: Tiro, Gades y Lixus.

¿Y qué decir del nombre Asteria que algunas fuentes greco-romanas (e.g. Cicerón, De natura deorum, III 42) dieron a la diosa madre del Heracles de Tiro? Independientemente de la paronimia que hace de este nombre griego un aceptable sustituto de Astarte, es difícil pensar que no estuviera presente aquí el recuerdo del nombre de la primera Delos, la isla que flota a merced de las olas.

No resulta fácil concluir un estudio que no está cerrado y maneja datos fragmentarios, evasivos o ambiguos. Lo que sí parece claro es que la serie toponímica de las islas errantes y el paralelismo de los esquemas míticos asociados nos orientan hacia un topos mediterráneo, probablemente muy antiguo, que hacía hincapié en la naturaleza híbrida y la precariedad de unos asentamientos insulares que no terminaban de ser completamente terrestres, dando a una divinidad tutelar la misión de librarlos de las potencias ctónicas y de las fuerzas destructoras del Caos. La intervención de Melqart-Heracles en Tiro y de Heracles-Honorato en Lérins representa un acto de apropiación civilizadora, atestiguado por los tres gestos que lo acompañan: matar la serpiente, enraizar la isla, abrir paso al agua fertilizante de la fuente. Puede sorprender el hecho de que el referente más exacto del esquema mítico revelado por la Vida de san Honorato no sea griego, sino fenicio, en una isla que sin embargo había pertenecido a Massalia. Pero las ideas y las creencias que circulaban en el Mediterráneo arcaico, siguiendo las estelas entrecruzadas de los marineros foceos y tirios, eran tan vagabundas como las propias islas Planesias.

\section{Bibliografía}

ALY, W. (1957): Strabon von Amaseia, IV. Bonn.

ARNAUD, P. (1998): “Les toponymes en -iana / -ianis des itinéraires : des villes de Ptolémée aux grands domaines ?", in Arnaud, P., Counillon, P. (ed.), Geographica historica, Bordeaux-Nice, 201-224.

ARNAUD, P. (2003): "Les îles de Lérins, SainteMarguerite et Saint-Honorat (Cannes, Alpes-
Maritimes)", in Pasqualini, P., Arnaud, P., Varaldo, C. (ed.), Des îles côte à côte. Histoire du peuplement des îles de l'Antiquité au Moyen Âge (Provence, Alpes-Maritimes, Ligurie, Toscane), Aix-en-Provence - Bordighera, 175-189.

ARNAUD, P. (2005): Les routes de la navigation antique. Itinéraires en Méditerranée. París.

BADIE, A., GAIllEDRAT, E., MORET, P., ROUILLARD, P., SILLIERES, P. (2000): Le site antique de La Picola à Santa Pola (Alicante). París.

BONNET, C. (1988): Melqart. Cultes et mythes de l'Héraclès tyrien en Méditerranée. Louvain (Studia Phoenicia, VIII).

CHANTRAINE, P. (1933): La formation des noms en grec ancien. París.

COOK, A.B. (1940): Zeus, a Study in Ancient Religion, III, 2. Cambridge.

COUPRY, J. \& VINDRY, G. (1982): "Lérôn et Lériné aux îles de Lérins. Un couvercle en ivoire, à dédicace grecque, découvert à l'île SainteMarguerite (Cannes)", Revue Archéologique de Narbonnaise, 15, 353-358.

DELAMARRE, X. (2003): Dictionnaire de la langue gauloise. Une approche linguistique du vieuxceltique continental. París.

DESANGES, J., ed. (2008): Pline, Histoire naturelle: Livre VI, $4^{e}$ Partie. L'Asie africaine sauf l'Egypte, les dimensions et les climats du monde habité. París.

DETIENNE, M. \& VERNANT, J.-P. (1974): Les ruses de l'intelligence. La mètis des Grecs. París.

DION, R. (1954): "Itinéraires maritimes occidentaux de l'Antiquité", Bull. Assoc. Géogr. fr., 243-244, 128-135.

DOMINGUEZ MONEDERO, A.J. (2002): “Greeks in Iberia: colonialism without colonization", in C.L. Lyons \& J. K. Papadopoulos (ed.), The archaeology of colonialism, Los Angeles, 65-95.

DUBLER, C.E. (1988): “Al-Andalus en la geografía de al-Idrîsî”, Studi Maghrebini 20, 113-151.

ETTLINGER, E. (1964): "The font at Stone", Buckinghamshire Record Society, 17, 257-265.

FRANGOULIS, H. (2008): "La fondation de Tyr chez Nonnos: influence d'Eratosthène", in Chr. Cusset et H. Frangoulis (ed.), Eratosthène : un athlète du savoir, Saint-Etienne, 137-148.

JOURDAIN-ANNEQUIN, C. (1989): Héraclès aux portes $d u$ soir. Mythe et histoire. Besançon. 
KRETTEK, A.M. (1911): Die Orstnamen der Vida de sant Honorat von Raimon Feraut und ihrer lateinischen Quelle. Halle.

LABROUSSE, M. (1995): Saint Honorat fondateur de Lérins et évêque d'Arles. Abbaye de Bellefontaine, Bégrolles-en-Mauges.

LACROIX, L. (1974): "Héraclès, héros voyageur et civilisateur", Bulletin des Lettres et Sciences morales et politiques de l'Académie royale de Belgique, 60, 34-59.

LEVY, E. (1894-1924): Provenzalisches SupplementWörterbuch. Leipzig.

MAYANS i SISCAR, J.A. (1771): Ilici, hoi la villa de Elche, ilustrada con varios discursos. Valencia.

MICHELOT, H. (1824): Portulan de la mer Méditerranée, ou Guide des pilotes côtiers. Marseille.

MONTIGLIO, Silvia (2005): Wandering in ancient Greek culture. Chicago.

MORET, P. (1997): "Planesiai, îles erratiques de l'Occident grec", Revue des Études Grecques 110 (1), 25-56.

MORET, P. (2006): "La formation d'une toponymie et d'une ethnonymie grecques de l'Ibérie : étapes et acteurs", in G. Cruz Andreotti, P. Le Roux, P. Moret (ed.), La invención de una geografía de la Península Ibérica, I. La época republicana, Málaga-Madrid, 39-76.

MORIS, H. (1909): L'abbaye de Lérins. Histoire et monuments. París.

MUNKE, B. (1911): Die Vita sancti Honorati nach drei Handschriften herausgegeben. Halle.

NENCI, G. \& VALLET, G., dir. (1994): Bibliografia topografica della colonizzazione greca in Italia e nelle isole Tirreniche, XIII. Pisa - Roma.

NISHIMURA-JENSEN， J. (2000): “Unstable Geographies: The Moving Landscape in Apollonius' Argonautica and Callimachus' Hymn to Delos", Transactions of the American Philological Association, 130, 287-317.

NOUAILHAT, R. (1988): Saints et patrons. Les premiers moines de Lérins. París.
PARKER, A.J. (1992): Ancient Shipwrecks of the Mediterranean \& the Roman Provinces. Oxford.

PEREZ BURGOS, J.M. (1997): “La excavación arqueológica de Urgencia Tabarca I (Isla de nueva Tabarca, Alicante)", Actas del XXIII Congreso Nacional de Arqueología - Elche 1995, Elche, 179-186.

PETRONE, G. (1988): "Nomen / omen : poetica e funzione dei nomi (Plauto, Seneca, Petronio)", Materiali e Discussioni per l'analisi dei testi classici, 20-21, Pisa, 33-70.

PRIVAT, J.-M., ed. (2006): Dragons, entre sciences et fictions. París, CNRS.

RAMOS FOLQUES, A. (1970): La Isla de Tabarca. Alicante.

REYT, Ph. (2000): "Les dragons de la crue", Cahiers de géographie du Québec, 44, 122, 127-145.

RIGAUD, Ph. (2003): "Les îles de la Provence (Liber insularum Provinciae). Essai sur la toponymie insulaire (XII ${ }^{\mathrm{e}}-\mathrm{XVI}^{\mathrm{e}}$ s.)", in Pasqualini, P., Arnaud, P., Varaldo, C. (ed.), Des îles côte à côte. Histoire du peuplement des îles de l'Antiquité au Moyen Âge (Provence, Alpes-Maritimes, Ligurie, Toscane), Aix-en-Provence - Bordighera, 45-66.

SCHMIDT, K. (1902): "Die griechischen Personennamen bei Plautus", Hermes 37, 353390.

SIMON, M. (1955): Hercule et le Christianisme. París, Les Belles Lettres.

SOMMIER, S. (1909): "L'isola di Pianosa nel Mar Tirreno", Riv. Geogr. Italiana 16, 1909, 441-464, $528-540$ y $585-606$.

SUWE, I. (1943): La Vida de Sant Honorat, poème provençal de Raimond Feraud publié d'après tous les manuscrits. Uppsala.

THEVENOT, J. de (1727): Relation d'un voyage fait au Levant. Amsterdam, $3^{\mathrm{a}}$ ed. $\left(1^{\mathrm{a}}\right.$ ed. París, 1664).

VALENTIN, M.D., ed. (1977): Sermo sancti Hilarii Arelatensis de vita sancti Honorati episcopi Arelatensis. París, Sources chrétiennes, 235.

WILL, E. (1950-1951): “Au Sanctuaire d'Héraclès à Tyr: l'olivier enflammé, les stèles et les roches ambrosiennes", Berytus 10, 1-12. 